\title{
Morphometric Study of the Normal Egyptian Coccyx from (Age 1-40 Year)
}

\section{Saadia Ahmed Shalaby, Essam Mohammed Eid, Omar ABd Alaziz Allam, Ali Mohammed Ali, Mohammad Abdullah Gebba*}

Anatomy and Embryology Department, Benha Faculty Of Medicine, Benha University, Benha City, Egypt

\author{
Email address: \\ mohammedgebba@gmail.com (M. A. Gebba)
}

\section{To cite this article:}

Saadia ahmed Shalaby, Essam Mohammed Eid, Omar ABd Alaziz Allam, Ali Mohammed Ali, Mohammad Abdullah Gebba. Morphometric Study of the Normal Egyptian Coccyx from (Age 1-40 Year). International Journal of Clinical and Developmental Anatomy.

Vol. 1, No. 2, 2015, pp. 32-41. doi: 10.11648/j.ijcda.20150102.13

\begin{abstract}
Background: Coccyx is named as resemblance to curved beak of the cuckoo. The coccyx is a triangular bone consisting of three to five segments: the first is the largest, it articulates with the sacrum. The last three segments are smaller and form a single bony piece. The anterior surface presents three transverse grooves indicating site of fusion of these segments. Aim of the Work: To study the normal variations of coccyx in number of segments, shape, size, curves, in different age groups by plain X-ray, MRI scan. Patients and Methods: Study was carried out on 200 normal Egyptian individuals, and were divided into 4 groups:- First group from the age of 1 up to $<6$ years. Second group from the age of 6 years up to $<12$ years. Third group from the age of 12 years up to $<20$ years. Fourth group from 20 years up to 40 years. Each one of these groups comprises 50 persons ( 25 males \& 25 females). A full medical history was taken and each individual was subjected for plain X-ray on the pelvis (Anteroposterior \& Lateral View) to study the variations of the coccyx, forty individuals were subjected to MRI scan as ten from each group. Results: Three coccygeal segments were present in $138(68.3 \%)$ of individuals. Most of the subjects had coccyx type I (82; 41.0\%) Fig.(2), II (63; 31.5\%), Fig.(3) III (25;12.5\%) Fig.(4)IV(19; 9.5\%) Fig.(5) and V(11; $5.5 \%$ ), Fig.(6) Type I being more common among males. Joint subluxation was significantly more present among females. The sacrococcygeal structures were longer in men than women. However the coccyx was more ventrally angulated among females. Conclusion: Most of the Egyptian adults have a gently curved forward, or straight, coccyx composed of 3 segments. Sacrococcygeal morphologic findings that are associated with coccydynia, such as joint subluxation, spicule, and lateral deviation of coccygeal tip, commonly present in adult persons.
\end{abstract}

Keywords: Coccyx Anatomy, Coccydynia, Coccygectomy

\section{Introduction}

The coccyx or tailbone is the most distal component of the vertebral column, consisting of multiple segments, and serves as a site of attachment for muscles and ligaments that build the perineum (1). Either idiopathic or with an underlying pathology, such as trauma, difficult childbirth, tumours, infections and sacrococcygeal or intercoccygeal joint instability, the coccygeal region can develop pain. This is referred to as coccydynia or coccygodynia. Patients with this condition experience pain in and around the coccyx that is usually exacerbated by prolonged sitting or standing, and when rising from a seated position. This pain is the result of an inflammatory process around the sacrococcygeal region that can be severe enough to limit regular daily activities. Nonsteroidal anti-inflammatory drugs, physical therapy, postural adjustments, local injections of steroid or anesthetics, coccygeal manipulation, extracorporeal shock wave therapy and radiofrequency ablation are used to treat this condition non-operatively. Nevertheless, surgical management (i.e. total coccygectomy or excision of the mobile segment) is warranted if the pain failed to respond to conservative treatment $(2,3)$.

The radiological classification of the coccyx was described. This classification revealed the morphology and morphometry of the coccyx can play a role in the development of coccydynia; for example, people with a coccyx that is markedly curved and pointing forward, sharply angled anteriorly or retroverted with spicule, have subluxation of the sacrococcygeal or intercoccygeal joints are at higher risk of developing coccygeal pain (4).

The diagnosis of coccydynia was based predominantly on clinical examination with static standard radiographs, CT, and 
MRI, which showed no particular abnormality except in the presence of tumour or infection. Coccydynia is a dynamic disorder which can only be appreciated on dynamic films. A method of assessing coccygeal mobility based on a comparison of static and dynamic lateral films with the hips flexed while the patient sat on a hard stool and extended the spine, producing more pain. The films were superimposed to compare and measure the sagittal movement of the coccyx in flexion and extension (5), the angles of sagittal pelvic rotation, the angle of mobility and the angle of incidence were calculated. The angle of sagittal rotation was measured based on the pivot angle made when the radiographs were superimposed, matching the sacrum. The angle of incidence measured the angle at which the coccyx struck the seat surface. The angle of mobility was the difference between the tips of the coccygeal segments in the two films. Based on the mobility of the coccyx, it was classified as normal, subluxated, immobile or hypermobile. (5).

Provocative discography has been found to be a more promising investigation in the assessment of coccydynia Coccygeal discography, a procedure similar to lumbar discography. Based on the objective evidence of degeneration as a cause of pain, assessment of the disc space using a discogram to reproduce the pain appears to be a more valid evaluation tool. (5).

Dynamic radiographs obtained in both the sitting and standing positions may be more useful than static X-rays because they allow for measurement of the sagittal rotation of the pelvis and the coccygeal angle of incidence. A comparison of sitting and standing films will yield radiographic abnormalities in up to $70 \%$ of symptomatic coccydynia cases. (6).

Advanced imaging modalities may be also be utilized to establish a diagnosis of coccydynia, although these techniques may not be as accurate as dynamic radiographs. Magnetic resonance imaging (MRI) and technetium Tc- 99m bone scans may demonstrate inflammation of the sacrococcygeal area indicative of coccygeal hyper mobility. Advanced imaging techniques can be used to exclude certain forms of underlying pathology such as chondroma. Provocative testing of the coccyx, such as pressing on the region with a blunted needle to elicit pain, and pain relief with the injection of local anesthetic under fluoroscopic guidance may also be useful in diagnosis as well. (6).

The aim of this work was to study the normal variations of coccyx in number, shape, size, curves, joints in between, mobility in different age groups by plain X-ray, MRI scan and on dried bone, structures attached to the coccyx and microstructure of the coccyx.

\section{Materials and Methods}

\subsection{The Studied Individual Groups}

Plain X-ray was carried out on the sacrum and coccyx of 200 normal healthy individuals including 100 males and 100 females their ages ranged from one year to forty years old.
The cases were selected from the outpatient clinics of Benha University Hospital and all X-rays were operated in the Hospital Radiology Department.

MRI was carried out on the sacrum and coccyx of 40 normal healthy individuals including 20 males and 20 females. The cases were selected from outpatient clinics of Alexandria and Ain-Shams Hospital and all MRI were operated in the Hospital Radiology Department.

In selection of cases for Plain X-ray and MRI, the following criteria were excluded:

1. History of back trauma.

2. Presence of any symptoms or signs that indicate a pelvic pathology.

3. Presence of abnormal coccygeal or sacral vertebral body on radiographs due to injury, deformity, degeneration, inflammation, tumour or other causes.

After exclusion of those individuals, The 200 individuals of both sexes, 100 males and 100 females, were divided into four main groups:

$\operatorname{Group}_{1}(\mathrm{G} 1)=$ from 1 year up to $<6$ year.

Group2 $(\mathrm{G} 2)=$ from 6 year up to $<12$ year.

Group3 $(\mathrm{G} 3)=$ from 12 year up to $<20$ year.

Group4 $(\mathrm{G} 4)=$ from 20 year up to 40 year.

Each group consists of 25 males and 25 females, these individuals will be gathered in four (sex/age) subgroups as shown in table (3).

Sacrococcygeal morphologic features including number of coccygeal segments, type of coccyx, and lateral deviation of coccygeal tip were recorded. Moreover, morphometric measurements including lengths and angles of the sacrococcygeal region were measured. The results of the variables were recorded from each group and analyzed statistically using p-value of $<0.05$ as the cut-off level of significance.

\subsection{The Parameters in Use}

In each age group, the following parameters (dimensions) were measured (in centimeters).

\subsubsection{Dimensions and Indices of the Sacrum: Fig.(1)}

i. The sacral straight length(SSL):

Measured in a straight line from the middle of the upper border of S1 to the middle of the inferior border of S5.

ii. The sacral curved length(SCL):

Average of the anterior and posterior curved sacral lengths measured from the upper border of S1 to the inferior border of S5

iii. Sacrococcygeal angle(SCA):

Formed by the intersection of a line between the midpoint of the upper borders of S1 and Co1 and a line between the latter and the tip of the coccyx.

\subsubsection{Dimensions and Indices of the Coccyx: Fig.(1)}

i. The coccygeal straight length(CSL):

Measured in a straight line from the middle of the upper border of Col to the coccygeal tip.

ii. The coccygeal curved length(CCL): 
Average of the anterior and posterior curved coccygeal lengths measured from the upper border of Co1 to the tip of the coccyx.

iii. The Lateral deviation of the tip of the $\operatorname{coccyx}(\mathrm{LDC})$ :

Formed between lines intersecting the middle of two adjacent coccyges (Co1-Co2 and Co2-Co3). Determined by measuring the angle between the tip of the coccyx and a line passing through the middle of the sacrum.
Plain X-ray was carried out on the sacrum and coccyx of 200 normal healthy individuals including 100 males $(M)$ and 100 females $(\mathrm{F})$, with an age ranged from one year to forty years old. The cases were divided into four main age groups:

Group $_{1}(\mathrm{G} 1)=$ from 1 year up to $<6$ year.

Group2 $(\mathrm{G} 2)=$ from 6 year up to $<12$ year.

Group $3(\mathrm{G} 3)=$ from 12 year up to $<20$ year.

Group4 $(\mathrm{G} 4)=$ from 20 year up to 40 year.

\section{Results}

Table (1). Showing the mean and standard deviation of age / years in the studied age groups in both sexes.

\begin{tabular}{lllll}
\hline & Sex & Males $(\mathbf{M})$ & & Females (F) \\
\cline { 3 - 6 } Age group / yrs & $\mathbf{N}$ & Mean \pm SD (years) & N & Mean \pm SD (years) \\
\hline $\mathrm{G}_{1}(1-<6$ yrs) & 25 case & $2.98 \pm 1.42$ & 25 case & $2.75 \pm 1.3$ \\
G2 $(6-<12$ yrs) & 25 case & $9.06 \pm 2.08$ & 25 case & $8.78 \pm 1.95$ \\
G3 $(12-<20$ yrs) & 25 case & $22.5 \pm 8.14$ & 25 case & $22.1 \pm 7.98$ \\
G4 (20-40 yrs) & 25 case & $31.4 \pm 5.7$ & 25 case & $31.1 \pm 5.1$ \\
\hline
\end{tabular}

$\mathrm{N}=$ Number of cases in each age/sex group.

$\mathrm{SD}=$ Standard deviation

$\mathrm{G}=$ Group, $\mathrm{M}=$ Male, $\mathrm{F}=$ Female

Forty individuals will be subjected to MRI scan as ten from each group.

The results were obtained from Plain X-ray and MRI, the variables measurements were recorded.

\subsection{Measurements of the Coccyx}

In male cases the Coccygeal Straight Length (CSL), was $3.07 \pm 0.20 \mathrm{~cm}$ in first age group $\left(\mathrm{MG}_{1}\right), 3.10 \pm 0.22 \mathrm{~cm}$ in second age group $\left(\mathrm{MG}_{2}\right), 3.36 \pm 0.28 \mathrm{~cm}$ in third age group $\left(\mathrm{MG}_{3}\right), 3.4 \pm 1.99 \mathrm{~cm}$ in fourth age group $\left(\mathrm{MG}_{4}\right)$, (table 2).

These data showed a statistical significant increase between $2^{\text {nd }}$ age $\operatorname{group}\left(\mathrm{MG}_{2}\right), 3^{\text {rd }}$ age $\operatorname{group}\left(\mathrm{MG}_{3}\right)$ the remaining age groups showed insignificant increase (table 3 ).

These data showed a statistical significant increase in this parameter between $2^{\text {nd }}$ female group $\left(\mathrm{FG}_{2}\right)$ and $3^{\text {rd }}$ female group $\left(\mathrm{FG}_{3}\right)$ the remaining age groups showed insignificant increase (table 5).

In male cases the Coccygeal curved Length (CCL), was $3.40 \pm 0.34 \mathrm{~cm}$ in first age group $\left(\mathrm{MG}_{1}\right), 3.41 \pm 0.35 \mathrm{~cm}$ in second age group $\left(\mathrm{MG}_{2}\right), 3.52 \pm 0.39 \mathrm{~cm}$ in third age $\operatorname{group}\left(\mathrm{MG}_{3}\right), 3.55 \pm 0.34 \mathrm{~cm}$ in fourth age $\operatorname{group}\left(\mathrm{MG}_{4}\right)$, (table 2) These data showed statistical non-significant change in these parameters among the four tested groups in males (table 3).

In female cases the Coccygeal curved Length (CCL), was $3.36 \pm 0.31 \mathrm{~cm}$ in first age group $\left(\mathrm{FG}_{1}\right), 3.39 \pm 0.32 \mathrm{~cm}$ in second age group $\left(\mathrm{FG}_{2}\right), 3.42 \pm 0.34 \mathrm{~cm}$ in third age $\operatorname{group}\left(\mathrm{FG}_{3}\right), 3.49 \pm 0.39 \mathrm{~cm}$ in fourth age group $\left(\mathrm{FG}_{4}\right)$, (table 4)

These parameters showed statistical insignificant increase in these parameters among the four tested groups in females (table 5).

In male cases the Lateral Deviation of the Coccyx (LDC), was $15^{\circ} \pm 0.57^{\circ}$ in first age group $\left(\mathrm{MG}_{1}\right), 15^{\circ} \pm 0.62^{\circ}$, in second age group $\left(\mathrm{MG}_{2}\right), 15.9^{\circ} \pm 0.64^{\circ}$ in third age group $\left(\mathrm{MG}_{3}\right), 16.2^{\circ} \pm 0.66^{\circ}$ in fourth age group $\left(\mathrm{MG}_{4}\right)$, (table 2 ).

These data showed statistical non-significant change in these parameters among the four tested groups in males (table 5).

In female cases the Lateral Deviation of the Coccyx (LDC), was $14.7^{\circ} \pm 0.61^{\circ}$ in first age group $\left(\mathrm{FG}_{1}\right), 15.3^{\circ} \pm 0.61^{\circ}$, in second age group $\left(\mathrm{FG}_{2}\right), 15.9^{\circ} \pm 0.71^{\circ}$ in third age group $\left(\mathrm{FG}_{3}\right), 16.1^{\circ} \pm 0.71^{\circ}$ in fourth age group $\left(\mathrm{FG}_{4}\right)$, (table 4$)$.

These data showed a statistical significant increase regarding this parameter in $2^{\text {nd }}$ female group $\left(\mathrm{FG}_{2}\right)$. However, in $3^{\text {rd }}$ female group(FG3) and fourth female group (FG4) these parameters showed insignificant increase (table 5).

\subsection{Measurements of Sacrum}

In male cases the Sacral Straight Length (SSL), was 9.80 $\pm 0.70 \mathrm{~cm}$ in first age group $\left(\mathrm{MG}_{1}\right), 9.92 \pm 0.73 \mathrm{~cm}$ in second age group $\left(\mathrm{MG}_{2}\right), 10.71 \pm 0.77 \mathrm{~cm}$ in third age group $\left(\mathrm{MG}_{3}\right), 10.86 \pm 0.79 \mathrm{~cm}$ in fourth age group $\left(\mathrm{MG}_{4}\right)$, (table 2)

These data showed a statistical non-significant increase in this index between the four consecutive age groups, however in $2^{\text {nd }}$ age group $\left(\mathrm{MG}_{2}\right)$ the mean value was statistically significant lower than the mean value obtained in 3rd group $\left(\mathrm{MG}_{3}\right)$ (table 3).

In female cases the Sacral Straight Length (SSL), was $9.81 \pm 0.68 \mathrm{~cm}$ in first age $\operatorname{group}\left(\mathrm{FG}_{1}\right), 9.90 \pm 0.70 \mathrm{~cm}$ in second age group $\left(\mathrm{FG}_{2}\right), 10.48 \pm 0.70 \mathrm{~cm}$ in third age $\operatorname{group}\left(\mathrm{FG}_{3}\right), 10.71 \pm 0.73 \mathrm{~cm}$ in fourth age $\operatorname{group}\left(\mathrm{FG}_{4}\right)$, (table 4)

These data showed a statistical significant increase in this parameter between $2^{\text {nd }}$ group $\left(\mathrm{FG}_{2}\right)$ and $3^{\text {rd }}$ group $\left(\mathrm{FG}_{3}\right)$ the remaining age groups showed insignificant increase (table 5). 
In male cases the Sacral Curved Length (SCL), was $10.70 \pm 0.84 \mathrm{~cm}$ in first age group $\left(\mathrm{MG}_{1}\right), 10.80 \pm 0.76 \mathrm{~cm}$ in second age group $\left(\mathrm{MG}_{2}\right), 11.61 \pm 0.57 \mathrm{~cm}$ in third age group $\left(\mathrm{MG}_{3}\right), 11.62 \pm 0.67 \mathrm{~cm}$ in fourth age $\operatorname{group}\left(\mathrm{MG}_{4}\right)$, (table 2)

These data showed a statistical insignificant increase regarding this parameter in the $1^{\text {st }}$ male group (MG1) and $2^{\text {nd }}$ male group(MG2). However, in $3^{\text {rd }}$ male group $\left(\mathrm{MG}_{3}\right)$ group the mean value was statistically significant higher than the mean value obtained in $2^{\text {nd }}$ male group $\left(\mathrm{MG}_{2}\right)$ group (table 3 ).

In female cases the Sacral Curved Length (SCL), was $10.08 \pm 0.71 \mathrm{~cm}$ in first age group $\left(\mathrm{FG}_{1}\right), 10.1 \pm 0.70 \mathrm{~cm}$ in second age group $\left(\mathrm{FG}_{2}\right), \quad 10.95 \pm 0.61 \mathrm{~cm}$ in third age group $\left(\mathrm{FG}_{3}\right), 10.99 \pm 0.61 \mathrm{~cm}$ in fourth age $\operatorname{group}\left(\mathrm{FG}_{4}\right)$, (table 4)

These parameters showed statistical insignificant change in these parameters among the four tested groups in females (table 5).

In male cases the Sacrococcygeal Angle(SCA), was $105.70^{\circ} \pm 1.75^{\circ}$ in first age group $\left(\mathrm{MG}_{1}\right), 110.64^{\circ} \pm 3.39^{\circ}$ in second age group $\left(\mathrm{MG}_{2}\right), 112.48^{\circ} \pm 3.16^{\circ}$ in third age group $\left(\mathrm{MG}_{3}\right), 113.96^{\circ} \pm 3.23^{\circ}$ in fourth age $\operatorname{group}\left(\mathrm{MG}_{4}\right)$, (table 2)

These data showed a statistical significant increase regarding this parameter in the first three consecutive age groups. However, in fourth male group $\left(\mathrm{MG}_{4}\right)$, the mean value was statistically insignificant higher than the mean value obtained in third male group $\left(\mathrm{MG}_{3}\right)$ (table 3 ).

In female cases the Sacrococcygeal Angle( $S C A)$, was $104.10^{\circ} \pm 1.61^{\circ}$ in first age group $\left(\mathrm{FG}_{1}\right), 108.6^{\circ} \pm 3.25^{\circ}$ in second age group $\left(\mathrm{FG}_{2}\right), 111.2^{\circ} \pm 3.08^{\circ}$ in third age $\operatorname{group}\left(\mathrm{FG}_{3}\right), 112.10^{\circ} \pm 3.61^{\circ}$ in fourth age $\operatorname{group}\left(\mathrm{FG}_{4}\right)$, (table 4)

These data showed a statistical significant increase in this index between the first three consecutive age groups, however in fourth female group $\left(\mathrm{FG}_{4}\right)$ the mean value was statistically insignificant higher than the mean value obtained in third female group $\left(\mathrm{FG}_{3}\right)$ (table 5).

\subsection{According to Age Groups}

\subsubsection{Coccyx}

\section{(i). Coccygeal Straight Length (CSL)}

In first age group $(1-<6$ years $)$ the mean Coccygeal straight length in male is $3.07 \pm 0.20 \mathrm{~cm}$, while in female is $3.01 \pm 0.19 \mathrm{~cm}$. This difference is non significant (table 6$10)$.

In second age group ( $6-<12$ years $)$ the mean Coccygeal straight length in male is $3.10 \pm 0.22 \mathrm{~cm}$, while in female is $3.17 \pm 0.21 \mathrm{~cm}$. This difference is nonsignificant (table 7$10)$.

In third age group $(12-<20$ years $)$ the mean Coccygeal straight length in male is $3.36 \pm 0.28 \mathrm{~cm}$, while in female is $3.27 \pm 0.26 \mathrm{~cm}$. This difference is significant (table 8-10).

In fourth age group (20-40 years) the mean Coccygeal straight length in male is $3.4 \pm 1.99 \mathrm{~cm}$, while in female is
$3.36 \pm 1.99 \mathrm{~cm}$. This difference is significant (table 9-10).

\section{(ii). Coccygeal Curved Length (CCL)}

In first age group $(1-<6$ years $)$ the mean Coccygeal curved length in male is $3.4 \pm 0.34 \mathrm{~cm}$, while in female is $3.36 \pm 0.31 \mathrm{~cm}$. This difference is non significant (table 611).

In second age group ( $6-<12$ years) the mean Coccygeal curved length in male is $3.41 \pm 0.35 \mathrm{~cm}$, while in female is $3.39 \pm 0.32 \mathrm{~cm}$. This difference is nonsignificant (table 711).

In third age group $(12-<20$ years $)$ the mean Coccygeal curved length in male is $3.52 \pm 0.39 \mathrm{~cm}$, while in female is $3.42 \pm 0.34 \mathrm{~cm}$. This difference is non-significant (table 811).

In fourth age group (20-40 years) the mean Coccygeal curved length in male is $3.55 \pm 0.34 \mathrm{~cm}$, while in female is $3.49 \pm 0.39 \mathrm{~cm}$. This difference is non-significant (table 911).

\section{(iii). Lateral Deviation of Coccyx (LCD)}

In first age group $(1-<6$ years $)$ the Lateral deviation of the coccyx in male is $15.0^{\circ} \pm 0.57^{\circ}$, while in female is $14.7^{\circ}$ $\pm 0.61^{\circ}$. This difference is non significant (table 6-12).

In second age group $(6-<12$ years) the Lateral deviation of the coccyx in male is $15^{\circ} \pm 0.62^{\circ}$, while in female is $15.3^{\circ}$ $\pm 0.61^{\circ}$. This difference is non-significant (table 7-12).

In third age group $(12-<20$ years) the Lateral deviation of the coccyx in male is $15.9^{\circ} \pm 0.64^{\circ}$, while in female is $15.9^{\circ} \pm 0.71^{\circ}$. This difference is nonsignificant (table 8-12).

In fourth age group (20-40 years) the Lateral deviation of the coccyx in male is $16.2^{\circ} \pm 0.66^{\circ}$, while in female is $16.1^{\circ}$ $\pm 0.71^{\circ}$. This difference is highly significant (table 9-12).

\subsubsection{The Sacrum}

\section{(i). Sacral Straight Length (SSL)}

In first age group ( $1-<6$ years) the mean Sacral straight length in male is $9.80 \pm 0.70 \mathrm{~cm}$, while in female is $9.81 \pm$ $0.68 \mathrm{~cm}$. This difference is non significant (table 6-13).

In second age group ( $6-<12$ years) the mean Sacral straight length in male is $9.92 \pm 0.73 \mathrm{~cm}$, while in female is $9.90 \pm 0.70 \mathrm{~cm}$. This difference is significant (table 7-13).

In third age group $(12-<20$ years $)$ the mean Sacral straight length in male is $10.71 \pm 0.77 \mathrm{~cm}$, while in female is $10.48 \pm 0.70 \mathrm{~cm}$. This difference is significant (table 8$13)$.

In fourth age group (20-40 years) the mean Sacral straight length in male is $10.86 \pm 0.79 \mathrm{~cm}$, while in female is $10.71 \pm 0.73 \mathrm{~cm}$. This difference is significant (table 913).

\section{(ii). Sacral Curved Length (SSL)}

In first age group $(1-<6$ years $)$ the mean Sacral curved length in male is $10.70 \pm 0.84 \mathrm{~cm}$, while in female is $10.08 \pm 0.71 \mathrm{~cm}$. This difference is significant (table 6-14).

In second age group ( $6-<12$ years) the mean curved straight length in male is $10.8 \pm 0.76 \mathrm{~cm}$, while in female is $10.1 \pm 0.70 \mathrm{~cm}$. This difference is significant (table 7-14). 
In third age group $(12-<20$ years $)$ the mean Sacral curved length in male is $11.61 \pm 0.57 \mathrm{~cm}$, while in female is $10.95 \pm 0.61 \mathrm{~cm}$. This difference is significant (table 8 14).

In fourth age group (20-40 years) the mean Sacral curved length in male is $11.62 \pm 0.67 \mathrm{~cm}$, while in female is 10.99 $\pm 0.61 \mathrm{~cm}$. This difference is significant (table 9-14).

\section{(iii). Sacrococcygeal Angle (SCA)}

In first age group $(1-<6$ years $)$ the mean Sacrococcygeal angle in male is $105.70^{\circ} \pm 1.75^{\circ}$, while in female is $104.10^{\circ} \pm 1.61^{\circ}$. This difference is non-significant (table 6-15).
In second age group $(6-<12$ years $)$ the mean Sacrococcygeal angle in male is $110.64^{\circ} \pm 3.39^{\circ}$, while in female is $108.6^{\circ} \pm 3.25^{\circ}$. This difference is non-significant (table 7-15).

In third age group $(12-<20$ years $)$ the mean Sacrococcygeal angle in male is $112.48^{\circ} \pm 3.16^{\circ}$, while in female is $111.2^{\circ} \pm 3.08^{\circ}$. This difference is non-significant (table 8-15).

In fourth age group (20-40 years) the mean Sacrococcygeal angle in male is $113.96^{\circ} \pm 3.23^{\circ}$, while in female is $112.1^{\circ} \pm 3.16^{\circ}$. This difference is non-significant (table 9-15).

Table (2). Shows the measured parameters of sacrum and coccyx according to the different male/age groups.

\begin{tabular}{|c|c|c|c|c|c|c|}
\hline & $\begin{array}{l}\text { CSL } \\
\text { MEAN } \pm S D(\mathrm{~cm})\end{array}$ & $\begin{array}{l}\text { CCL } \\
\text { MEAN } \pm S D(\mathrm{~cm})\end{array}$ & $\begin{array}{l}\text { LDC } \\
\text { MEAN } \pm S D \text { (degree) }\end{array}$ & $\begin{array}{l}\text { SSL } \\
\text { MEAN } \pm S D(\mathrm{~cm})\end{array}$ & $\begin{array}{l}\text { SCL } \\
\text { MEAN } \pm S D(\mathrm{~cm})\end{array}$ & $\begin{array}{l}\text { SCA } \\
\text { MEAN } \pm S D \text { (degree) }\end{array}$ \\
\hline MG1 & $3.07 \pm 0.20$ & $3.40 \pm 0.34$ & $15^{\circ} \pm 0.57^{\circ}$ & $9.80 \pm 0.70$ & $10.7 \pm 0.84$ & $105.70^{\circ} \pm 1.75^{\circ}$ \\
\hline MG2 & $3.10 \pm .022$ & $3.41 \pm 0.35$ & $15^{\circ} \pm 0.62^{\circ}$ & $9.92 \pm 0.73$ & $10.8 \pm 0.76$ & $110.64^{\circ} \pm 3.39^{\circ}$ \\
\hline MG3 & $3.36 \pm 0.28$ & $3.52 \pm 0.39$ & $15.9^{\circ} \pm 0.64^{\circ}$ & $10.71 \pm 0.77$ & $11.61 \pm 0.57$ & $112.48^{\circ} \pm 3.16^{\circ}$ \\
\hline MG4 & $3.4 \pm 1.99$ & $3.55 \pm 0.34$ & $16.2^{\circ} \pm 0.66^{\circ}$ & $10.86 \pm 0.79$ & $11.62 \pm 0.67$ & $113.96^{\circ} \pm 3.23^{\circ}$ \\
\hline
\end{tabular}

Table (3). Shows the measured parameters of sacrum and coccyx according to age and sex.

\begin{tabular}{|c|c|c|c|c|}
\hline & MG1 & MG2 & $\mathbf{t}$ & $\mathbf{P}$ \\
\hline CSL & $3.07 \pm 0.20$ & $3.10 \pm .022$ & 0.87 & $>0.05$ \\
\hline CCL & $3.40 \pm 0.34$ & $3.41 \pm 0.35$ & 0.97 & $>0.05$ \\
\hline LDC & $15^{\circ} \pm 0.57^{\circ}$ & $15^{\circ} \pm 0.62^{\circ}$ & 0.14 & $>0.05$ \\
\hline SSL & $9.8 \pm 0.70$ & $9.92 \pm 0.73$ & 1.08 & $>0.05$ \\
\hline SCL & $10.7 \pm 0.84$ & $10.8 \pm 0.76$ & 0.77 & $>0.05$ \\
\hline SCA & $105.70^{\circ} \pm 1.75^{\circ}$ & $110.64^{\circ} \pm 3.39^{\circ}$ & 2.01 & $<0.05^{*}$ \\
\hline CSL & $3.10 \pm .022$ & $3.36 \pm 0.28$ & 2.14 & $<0.05^{*}$ \\
\hline $\mathrm{CCL}$ & $3.41 \pm 0.35$ & $3.52 \pm 0.39$ & 1.65 & $>0.05$ \\
\hline LDC & $15^{\circ} \pm 0.62^{\circ}$ & $15.9^{\circ} \pm 0.64^{\circ}$ & 1.34 & $>0.05$ \\
\hline SSL & $9.92 \pm 0.73$ & $10.71 \pm 0.77$ & 2.11 & $<0.05^{*}$ \\
\hline SCL & $10.8 \pm 0.76$ & $11.61 \pm 0.57$ & 2.54 & $<0.05^{*}$ \\
\hline \multirow[t]{2}{*}{ SCA } & $110.64^{\circ} \pm 3.39^{\circ}$ & $112.48^{\circ} \pm 3.16^{\circ}$ & 1.98 & $<0.05^{*}$ \\
\hline & MG3 & MG4 & $\mathrm{t}$ & $\mathrm{P}$ \\
\hline CSL & $3.36 \pm 0.28$ & $3.4 \pm 1.99$ & 1.07 & $>0.05$ \\
\hline CCL & $3.52 \pm 0.39$ & $3.55 \pm 0.34$ & 0.98 & $>0.05$ \\
\hline LDC & $15.9^{\circ} \pm 0.64^{\circ}$ & $16.2^{\circ} \pm 0.66^{\circ}$ & 0.88 & $>0.05$ \\
\hline SSL & $10.71 \pm 0.77$ & $10.86 \pm 0.79$ & 0.89 & $>0.05$ \\
\hline SCL & $11.61 \pm 0.57$ & $11.62 \pm 0.67$ & 0.28 & $>0.05$ \\
\hline SCA & $112.48^{\circ} \pm 3.16^{\circ}$ & $113.96^{\circ} \pm 3.23^{\circ}$ & 0.84 & $>0.05$ \\
\hline
\end{tabular}

Table (4). Shows the measured parameters of sacrum and coccyx according to the different female/age groups.

\begin{tabular}{|c|c|c|c|c|c|c|}
\hline & $\begin{array}{l}\text { CSL } \\
\text { MEAN } \pm S D(c m)\end{array}$ & $\begin{array}{l}\text { CCL } \\
\text { MEAN } \pm S D(c m)\end{array}$ & $\begin{array}{l}\text { LDC } \\
\text { MEAN } \pm \text { SD } \\
\text { (degree) }\end{array}$ & $\begin{array}{l}\text { SSL } \\
\text { MEAN } \pm S D(c m)\end{array}$ & $\begin{array}{l}\text { SCL } \\
\text { MEAN } \pm S D(\mathrm{~cm})\end{array}$ & $\begin{array}{l}\text { SCA } \\
\text { MEAN } \pm S D \text { (degree) }\end{array}$ \\
\hline FG1 & $3.01 \pm 0.19$ & $3.36 \pm 0.31$ & $14.7^{\circ} \pm 0.61^{\circ}$ & $9.81 \pm 0.68$ & $10.08 \pm 0.71$ & $104.1^{\circ} \pm 1.61^{\circ}$ \\
\hline FG2 & $3.17 \pm .021$ & $3.39 \pm 0.32$ & $15.3^{\circ} \pm 0.61^{\circ}$ & $9.90 \pm 0.70$ & $10.1 \pm 0.70$ & $108.6^{\circ} \pm 3.52^{\circ}$ \\
\hline FG3 & $3.27 \pm .026$ & $3.42 \pm 0.34$ & $15.9^{\circ} \pm 0.71^{\circ}$ & $10.48 \pm 0.70$ & $10.95 \pm 0.61$ & $111.2^{\circ} \pm 3.08^{\circ}$ \\
\hline FG4 & $3.36 \pm 1.99$ & $3.49 \pm 0.39$ & $16.1^{\circ} \pm 0.71^{\circ}$ & $10.71 \pm 0.73$ & $10.99 \pm 0.61$ & $112.1^{\circ} \pm 3.16^{\circ}$ \\
\hline
\end{tabular}

Table (5). Shows the measured parameters of sacrum and coccyx according to age and sex.

\begin{tabular}{lllll}
\hline & FG1 & FG2 & t & P \\
\hline CSL & $3.01 \pm 0.19$ & $3.17 \pm .021$ & 1.15 & $>0.05$ \\
CCL & $3.36 \pm 0.31$ & $3.39 \pm 0.32$ & 0.98 & $>0.05$ \\
\hline
\end{tabular}




\begin{tabular}{|c|c|c|c|c|}
\hline & FG1 & FG2 & $\mathrm{t}$ & $\mathbf{P}$ \\
\hline LDC & $14.7^{\circ} \pm 0.61^{\circ}$ & $15.3^{\circ} \pm 0.61^{\circ}$ & 2.05 & $<0.05^{*}$ \\
\hline SSL & $9.81 \pm 0.68$ & $9.90 \pm 0.70$ & 1.08 & $>0.05^{*}$ \\
\hline SCL & $10.08 \pm 0.71$ & $10.1 \pm 0.70$ & 0.98 & $>0.05$ \\
\hline \multirow[t]{2}{*}{ SCA } & $104.1^{\circ} \pm 1.61^{\circ}$ & $108.6^{\circ} \pm 3.52^{\circ}$ & 2.11 & $<0.05^{*}$ \\
\hline & FG2 & FG3 & $\mathrm{t}$ & $\mathrm{P}$ \\
\hline CSL & $3.17 \pm .021$ & $3.27 \pm .026$ & 2.10 & $<0.05 *$ \\
\hline CCL & $3.39 \pm 0.32$ & $3.42 \pm 0.34$ & 1.11 & $>0.05$ \\
\hline LDC & $15.3^{\circ} \pm 0.61^{\circ}$ & $15.9^{\circ} \pm 0.71^{\circ}$ & 1.18 & $>0.05$ \\
\hline SSL & $9.90 \pm 0.70$ & $10.48 \pm 0.70$ & 1.95 & $<0.05^{*}$ \\
\hline SCL & $10.1 \pm 0.70$ & $10.95 \pm 0.61$ & 0.98 & $>0.05$ \\
\hline \multirow[t]{2}{*}{ SCA } & $108.6^{\circ} \pm 3.52^{\circ}$ & $111.2^{\circ} \pm 3.08^{\circ}$ & 2.41 & $<0.05 *$ \\
\hline & FG3 & FG4 & $\mathrm{t}$ & $\mathrm{P}$ \\
\hline CSL & $3.27 \pm .026$ & $3.36 \pm 1.99$ & 1.32 & $>0.05$ \\
\hline CCL & $3.42 \pm 0.34$ & $3.49 \pm 0.39$ & 0.108 & $>0.05$ \\
\hline LDC & $15.9^{\circ} \pm 0.71^{\circ}$ & $16.1^{\circ} \pm 0.71^{\circ}$ & 0.89 & $>0.05$ \\
\hline SSL & $10.48 \pm 0.70$ & $10.71 \pm 0.73$ & 0.65 & $>0.05$ \\
\hline SCL & $10.95 \pm 0.61$ & $10.99 \pm 0.61$ & 0.78 & $>0.05$ \\
\hline $\mathrm{SCA}$ & $111.2^{\circ} \pm 3.08^{\circ}$ & $112.1^{\circ} \pm 3.16^{\circ}$ & 0.98 & $>0.05$ \\
\hline
\end{tabular}

Table (6). Shows the measured parameters of sacrum and coccyx according to age and sex in males and females at the age of (1-<6 years).

\begin{tabular}{llllll}
\hline & MG1 & FG1 & t & p \\
\hline \multirow{4}{*}{ Coccyx } & Coccygeal straight length & $3.07 \pm 0.20$ & $3.01 \pm 0.19$ & 0.952 & $>0.05$ \\
& Coccygeal Curved length & $3.4 \pm 0.34$ & $3.36 \pm 0.31$ & 0.822 & $>0.05$ \\
& Lateral deviation of coccyx & $15.0^{\circ} \pm 0.57^{\circ}$ & $14.7^{\circ} \pm 0.61^{\circ}$ & 1.223 & $>0.05$ \\
\multirow{3}{*}{ Sacrum } & Sacral straight Length & $9.80 \pm 0.70$ & $9.81 \pm 0.68$ & 0.711 & $>0.05$ \\
& Sacral curved Length & $10.70 \pm 0.84$ & $10.08 \pm 0.71$ & 0.69 & $<0.05$ \\
& Sacrococcygeal angle & $105.70^{\circ} \pm 1.75^{\circ}$ & $104.10^{\circ} \pm 1.61^{\circ}$ & 1.06 & $>0.05$ \\
\hline
\end{tabular}

Table (7). Shows the measured parameters of sacrum and coccyx according to age and sex in males and females at the age of(6-<12 years).

\begin{tabular}{llllll}
\hline & & MG2 & FG2 & t & P \\
\hline \multirow{4}{*}{ Coccyx } & Coccygeal straight length & $3.10 \pm 0.22$ & $3.17 \pm 0.21$ & 2.05 & $>0.05$ \\
& Coccygeal Curved length & $3.41 \pm 0.35$ & $3.39 \pm 0.32$ & 2.11 & $>0.05$ \\
& Lateral deviation of coccyx & $15^{\circ} \pm 0.62^{\circ}$ & $15.3^{\circ} \pm 0.61^{\circ}$ & 0.711 & $>0.05$ \\
\multirow{3}{*}{ Sacrum } & Sacral straight Length & $9.92 \pm 0.73$ & $9.90 \pm 0.70$ & 0.36 & $<0.05$ \\
& Sacral curved Length & $10.8 \pm 0.76$ & $10.1 \pm 0.70$ & 0.81 & $<0.05$ \\
& Sacrococcygeal angle & $110.64^{\circ} \pm 3.39^{\circ}$ & $108.6^{\circ} \pm 3.25^{\circ}$ & 1.68 & $>0.05$ \\
\hline
\end{tabular}

Table (8). Shows the measured parameters of sacrum and coccyx according to age and sex in males and females at the age of $(12<20) y e a r s$.

\begin{tabular}{llllll}
\hline & & MG3 & FG3 & t & P \\
\hline \multirow{4}{*}{ Coccyx } & Coccygeal straight length & $3.36 \pm 0.28$ & $3.27 \pm 0.26$ & 0.94 & $<0.05$ \\
& Coccygeal Curved length & $3.52 \pm 0.39$ & $3.42 \pm 0.34$ & 1.98 & $>0.05$ \\
& Lateral deviation of coccyx & $15.9^{\circ} \pm 0.64^{\circ}$ & $15.9^{\circ} \pm 0.71^{\circ}$ & 0.67 & $>0.05$ \\
\multirow{3}{*}{ Sacrum } & Sacral straight Length & $10.71 \pm 0.77$ & $10.48 \pm 0.70$ & 0.38 & $<0.05$ \\
& Sacral curved Length & $11.61 \pm 0.57$ & $10.95 \pm 0.61$ & 1.60 & $<0.05$ \\
& Sacrococcygeal angle & $112.48^{\circ} \pm 3.16^{\circ}$ & $111.2^{\circ} \pm 3.08^{\circ}$ & 1.17 & $>0.05$ \\
\hline
\end{tabular}

Table (9). Shows the measured parameters of sacrum and coccyx according to age and sex in males and females at the age of (20-40) years.

\begin{tabular}{llllll}
\hline & & MG4 & FG4 & t & P \\
\hline \multirow{3}{*}{ Coccyx } & Coccygeal straight length & $3.4 \pm 1.99$ & $3.36 \pm 1.99$ & 1.98 & $<0.05$ \\
& Coccygeal Curved length & $3.55 \pm 0.34$ & $3.49 \pm 0.39$ & 1.9 & $<0.05$ \\
& Lateral deviation of coccyx & $16.2^{\circ} \pm 0.66^{\circ}$ & $16.1^{\circ} \pm 0.71^{\circ}$ & 2.68 & $<0.01$ \\
\multirow{3}{*}{ Sacrum } & Sacral straight Length & $10.86 \pm 0.79$ & $10.71 \pm 0.73$ & 3.02 & $<0.05$ \\
& Sacral curved Length & $11.62 \pm 0.67$ & $10.99 \pm 0.61$ & 3.26 & $<0.05$ \\
& Sacrococcygeal angle & $113.96^{\circ} \pm 3.23^{\circ}$ & $112.1^{\circ} \pm 3.16^{\circ}$ & 1.58 & $>0.05$ \\
\hline
\end{tabular}


Table (10). Comparison between the four studied age groups regarding Coccygeal straight length.

\begin{tabular}{llllll}
\hline Coccygeal straight length & Gp. I (1-<6) (cm) & Gp.II (6-<12) (cm) & Gp. III (12-<20) (cm) & Gp. IV (20-40) (cm) & Total \\
\hline Range & $2.7-3.40$ & $2.7-3.40$ & $2.9-3.80$ & $2.9-3.80$ & $2.7-3.80$ \\
Mean \pm S.D. & $3.05 \pm 0.21$ & $3.10 \pm 0.22$ & $3.32 \pm 0.28$ & $3.33 \pm 0.28$ & $3.19 \pm 0.28$ \\
P & 0.107 & 0.11 & $0.021 *$. & $0.021^{*}$ & \\
\hline
\end{tabular}

Table (11). Comparison between the four studied age groups regarding Coccygeal curved length.

\begin{tabular}{llllll}
\hline Coccygeal curved length & Gp. I (1-<6) (cm) & Gp.II (6-< 12) (cm) & Gp. III (12-<20) (cm) & Gp. IV (20-40) (cm) & Total \\
\hline Range & $2.9-3.90$ & $2.9-3.90$ & $3-4.10$ & $3-4.10$ & $2.9-4.10$ \\
Mean \pm S.D. & $3.40 \pm 0.34$ & $3.43 \pm 0.35$ & $3.52 \pm 0.39$ & $3.55 \pm 0.34$ & $3.49 \pm 0.36$ \\
P & 0.21 & 0.102 & 0.11 & 0.254 & \\
\hline
\end{tabular}

Table (12). Comparison between the four studied age groups regarding Lateral deviation of the tip of the coccyx.

\begin{tabular}{llllll}
\hline $\begin{array}{l}\text { Lateral deviation of } \\
\text { coccyx }\end{array}$ & Gp. I (1-<6) (degree) & Gp.II (6-<12) (degree) & Gp. III (12-<20) (degree) & Gp. IV (20-40) (degree) & Total \\
\hline Range & $14^{\circ} .0-16^{\circ} .0$ & $14.5^{\circ}-16.5$ & $14.8^{\circ}-17^{\circ}$ & $14.8^{\circ}-17^{\circ}$ & $14 .^{\circ}-17^{\circ}$ \\
Mean \pm S.D. & $15^{\circ}-0.57^{\circ}$ & $15.5^{\circ}-0.62$ & $15.9^{\circ}-0.64$ & $16.2^{\circ}-0.66^{\circ}$ & $15.5^{\circ}-0.70^{\circ}$ \\
P & 0.211 & 0.310 & 0.107 & 0.166 \\
\hline
\end{tabular}

Table (13). Comparison between the four studied age groups regarding Sacral straight length.

\begin{tabular}{llllll}
\hline Sacral straight length & Gp. I (1-<6) (cm) & Gp.II (6-< 12) (cm) & Gp. III (12-<20) (cm) & Gp. IV (20-40) (cm) & Total \\
\hline Range & $8.5-11.30$ & $8.5-11.50$ & $9.5-12.20$ & $9.6-12.50$ & $8.5-12.50$ \\
Mean \pm S.D. & $9.90 \pm 0.76$ & $9.80 \pm 0.79$ & $10.71 \pm 0.69$ & $10.86 \pm 0.73$ & $10.32 \pm 0.88$ \\
P & 0.102 & 0.098 & $0.002 *$. & $0.013^{*}$ & \\
\hline
\end{tabular}

Table (14). Comparison between the four studied age groups regarding Sacral curved length.

\begin{tabular}{llllll}
\hline Sacral curved length & Gp. I (1-<6) (cm) & Gp.II (6-<12) (cm) & Gp. III (12-<20) (cm) & Gp. IV (20-40) (cm) & Total \\
\hline Range & $9.37-12.27$ & $9.27-12.27$ & $10.37-12.77$ & $10.37-13.07$ & $9.27--13.07$ \\
Mean \pm S.D. & $10.70 \pm 0.84$ & $10.80 \pm 0.84$ & $11.61 \pm 0.57$ & $11.62 \pm 0.67$ & $11.18 \pm 0.84$ \\
P & 0.086 & $0.041^{*}$ & $0.013^{*}$. & $0.002^{*}$ & \\
\hline
\end{tabular}

Table (15). Comparison between the four studied age groups regarding Sacrococcygeal angle.

\begin{tabular}{llllll}
\hline Sacrococcygeal angle & Gp. I (1-<6) (degree) & Gp.II (6-<12) degree) & Gp. III (12-<20) (degree) & Gp. IV (20-40) (degree) & Total \\
\hline Range & $102^{\circ}-109^{\circ} .0$ & $107^{\circ}-118^{\circ}$ & $107^{\circ}-117^{\circ}$ & $107^{\circ}-118^{\circ}$ & $102 .^{\circ}-118^{\circ}$ \\
Mean \pm S.D. & $105.7^{\circ}-1.75^{\circ}$ & $110.64^{\circ}-3.39^{\circ}$ & $112.48^{\circ}-3.16^{\circ}$ & $113.96^{\circ}-3.23^{\circ}$ & $110.45^{\circ}-4.03^{\circ}$ \\
$\mathrm{P}$ & 0.231 & 0.312 & 0.104 & 0.221 & \\
\hline
\end{tabular}

\section{Discussion}

\subsection{Measurements of Sacrum}

It's essential to calculate dimensions of sacrum to estimate parameters of the coccyx as sacrococcygeal angle.

In the present study, the mean value in the male groups of the Sacral straight length: (SSL), were increased steadily by advanced age but These data showed a statistical nonsignificant increase in this index between the four consecutive age groups, however in $2^{\text {nd }}$ age group $\left(\mathrm{MG}_{2}\right)$ the mean value was statistically significant lower than the mean value obtained in 3rd group $\left(\mathrm{MG}_{3}\right)$.

While in female groups of the Sacral straight length: (SSL), they showed a statistical significant increase in this parameter between $2^{\text {nd }}$ group $\left(\mathrm{FG}_{2}\right)$ and $3^{\text {rd }}$ group $\left(\mathrm{FG}_{3}\right)$ the remaining age groups showed insignificant increase.
In fourth age group (20-40 years) the mean Sacral straight length in male is $10.86 \pm 0.79 \mathrm{~cm}$, while in female is $10.71 \pm$ $0.73 \mathrm{~cm}$. This difference is significant.

These obtained results were in agreement with (1), (7) , (4), (8), (2) they all found that sacral straight length is increased steadily with age and always greater in male groups than female groups.

However, (1) , (7), (9) found that In fourth age group(2040 years) of European individuals the mean Sacral straight length in male is $11.2 \pm 1.0 \mathrm{~cm}$, while in female is $10.8 \pm 0.8$ $\mathrm{cm}$. This difference is significant. these measurements are higher than Egyptian individuals of the same age and sex.

The mean value in the male groups of the Sacral curved length: (SCL), were increased steadily by advanced age in both male and female groups but showed a statistical insignificant increase regarding this parameter in the $1^{\text {st }}$ male group (MG1) and $2^{\text {nd }}$ male group(MG2). However, in $3^{\text {rd }}$ 
male group $\left(\mathrm{MG}_{3}\right)$ group the mean value was statistically significant higher than the mean value obtained in $2^{\text {nd }}$ male group $\left(\mathrm{MG}_{2}\right)$ group The mean value in the male groups of the Sacral curved length: (SCL), These parameters showed statistical insignificant change in these parameters among the four tested groups in females $(\mathrm{P}>0.05)$.

In fourth age group (20-40 years) the mean Sacral curved length in male is $11.62 \pm 0.67 \mathrm{~cm}$, while in female is $10.99 \pm$ $0.61 \mathrm{~cm}$. This difference is significant.

These obtained results were in agreement with (1), (7) , (4), (8), (2) they all found that coccygeal curved length is increased steadily with age and always greater in male groups than female groups.

However, Woon and Stringer (1) Karadimas EJ. et al. (3) found that In fourth age group(20-40 years) of European individuals the mean Sacral curved length in male is $12.4 \pm$ $1.0 \mathrm{~cm}$, while in female is $12.1 \pm 0.9 \mathrm{~cm}$. This difference is significant. these measurements are higher than Egyptian individuals of the same age and sex.

The mean value in the male and female groups of the Sacrococcygeal angle: (SCD), These data showed a statistical significant increase regarding this parameter in the first three consecutive age groups. However, in fourth group , the mean value was statistically insignificant higher than the mean value obtained in third group in both male and female.

In fourth age group (20-40 years) the mean Sacrococcygeal angle in male is $113.96^{\circ} \pm 3.23^{\circ}$, while in female is $112.1^{\circ} \pm 3.16^{\circ}$. This difference is non-significant.

These obtained results were in agreement with (1) , (7) , (4), (8), (2) they all found that Sacrococcygeal angle is increased steadily with age and always greater in male groups than female groups.

However, Woon and Stringer (1) Karadimas EJ. et al. (3) found that In fourth age group(20-40 years) of European individuals the mean Sacrococcygeal angle in male is $168^{\circ} \pm$ $11^{\circ}$, while in female is $164^{\circ} \pm 13^{\circ}$. This difference is significant. these measurements are higher than Egyptian individuals of the same age and sex.

\subsection{Measurements of Coccyx}

In the present study, the mean value in the male groups of the Coccygeal straight length: (CSL), were increased steadily by advanced age but showed a statistical significant increase between $2^{\text {nd }}$ age group $\left(\mathrm{MG}_{2}\right), 3^{\text {rd }}$ age group $\left(\mathrm{MG}_{3}\right)(\mathrm{P}<0.05)$. the remaining age groups showed insignificant increase $(\mathrm{P}>$ $0.05)$.

While in female groups of the Coccygeal straight length: (CSL), they were also increased steadily by advanced age, but showed a statistical significant increase in this parameter between $2^{\text {nd }}$ female group $\left(\mathrm{FG}_{2}\right)$ and $3^{\text {rd }}$ female group $\left(\mathrm{FG}_{3}\right)$ the remaining age groups showed insignificant increase.

In fourth age group (20-40 years) the mean Coccygeal straight length in male is $3.4 \pm 1.99 \mathrm{~cm}$, while in female is $3.36 \pm 1.99 \mathrm{~cm}$. This difference is significant.

These obtained results were in agreement with (1), (3) (9), (10), they all found that coccygeal straight length is increased steadily with age and always greater in male groups than female groups.

However, (11) found that In fourth age group(20-40 years) of European individuals the mean Coccygeal straight length in male is $4.4 \pm 0.8 \mathrm{~cm}$, while in female is $4.0 \pm 0.8 \mathrm{~cm}$. This difference is significant. these measurements are higher than Egyptian individuals of the same age and sex.

The mean value in the male and female groups of the Coccygeal curved length: (CCL), were increased steadily by advanced age in both male and female groups but showed statistical non-significant change in these parameters among the four tested groups in both male and female $(\mathrm{P}>0.05)$. In fourth age group (20-40 years) the mean Coccygeal curved length in male is $3.55 \pm 0.34 \mathrm{~cm}$, while in female is $3.49 \pm$ $0.39 \mathrm{~cm}$. This difference is non-significant.

These obtained results were in agreement with (1) , (12), they all found that coccygeal curved length is increased steadily with age and always greater in male groups than female groups.

However, (13),(14),(15),(16) found that In fourth age group(20-40 years) of European individuals the mean Coccygeal curved length in male is $3.9 \pm 0.7 \mathrm{~cm}$, while in female is $3.6 \pm 0.7 \mathrm{~cm}$. This difference is significant. these measurements are higher than Egyptian individuals of the same age and sex.

The mean value in the male and female groups of the Lateral deviation of the coccyx: (LDC), were increased steadily by advanced age in both male and female groups but showed statistical non-significant change in these parameters among the four tested groups in both male and female $(\mathrm{P}>$ $0.05)$.

In fourth age group (20-40 years) the Lateral deviation of the coccyx in male is $16.2^{\circ} \pm 0.66^{\circ}$, while in female is $16.1^{\circ}$ $\pm 0.71^{\circ}$. This difference is highly significant. These obtained results were in agreement with (18), (19) they all found that Lateral deviation of the coccyx is increased steadily with age and always greater in male groups than female groups. However, (19),(20) found that In fourth age group(20-40 years) of European individuals the Lateral deviation of the coccyx in male is $15.7^{\circ} \pm 12.1^{\circ}$, while in female is $14.1^{\circ} \pm 11^{\circ}$. This difference is non-significant. these measurements are lower than Egyptian individuals of the same age and sex.
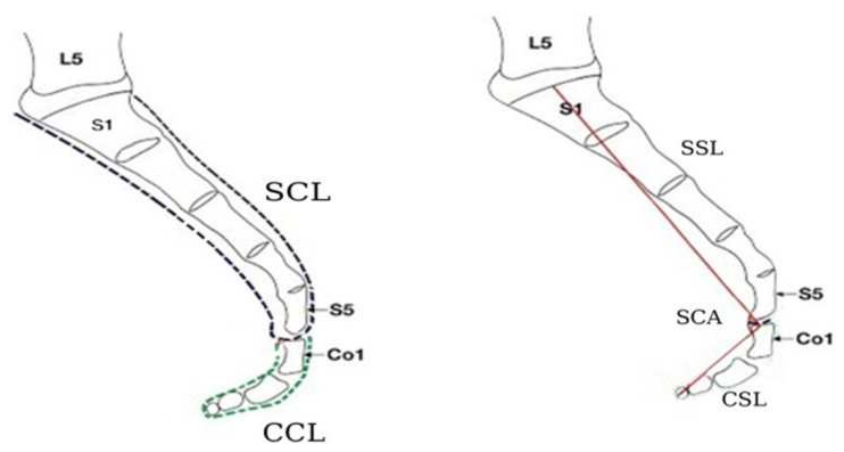

Fig. (1). Schematic diagram of the sacrum and coccyx in sagittal view showing the following diameters: CSL-Coccygeal straight length. CCLCoccygeal curved length SSL-Sacral straight length SCL-Sacral curved length and SCA-Sacrococcygeal angle. (Woon and Stringer 2012)(1). 


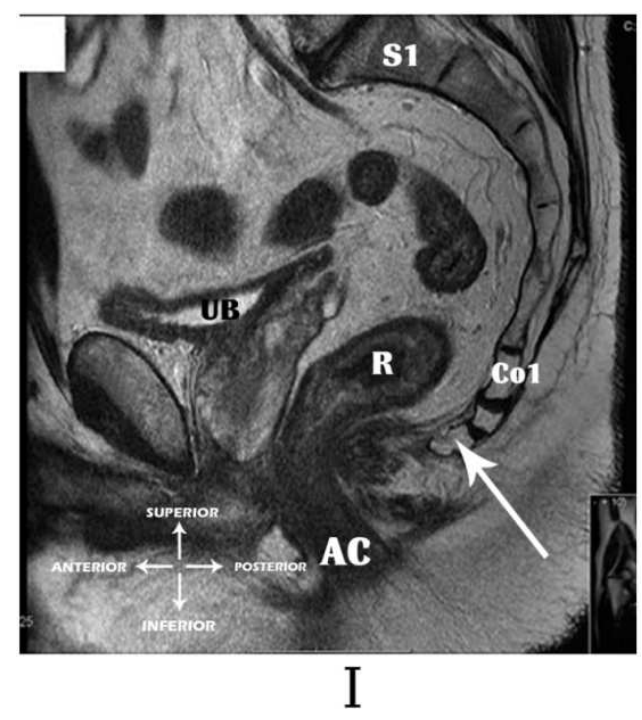

Fig. (2). A photograph of MRI (lateral view) of a male aged -40- year showing : Type I coccyx (Slightly curved and pointing downward).

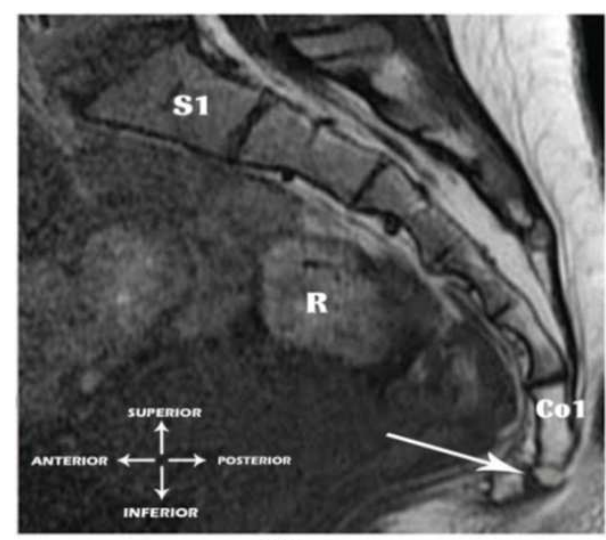

\section{II}

Fig. (3). A photograph of MRI (lateral view) of a female 35 year old showing Type II coccyx (Has a marked curve with the apex pointing forward).

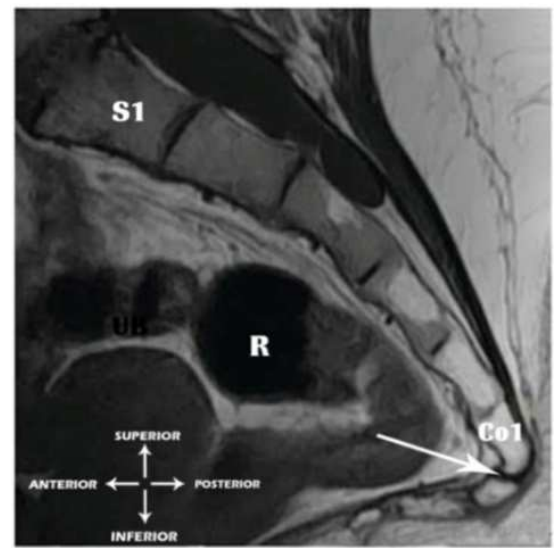

III

Fig. (4). A photograph of MRI (lateral view) of a male 28 year old showing Type III coccyx (Joint fusion angled forward sharply between first and second segments).

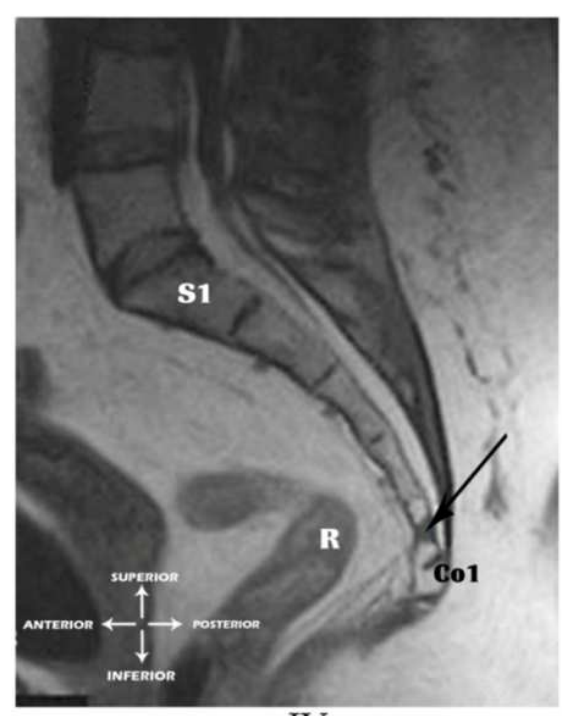

IV

Fig. (5). A photograph of MRI (lateral view) of a male 28 year old showing Type IV coccyx((Anteriorly subluxated at the level of the sacrococcygeal joint).

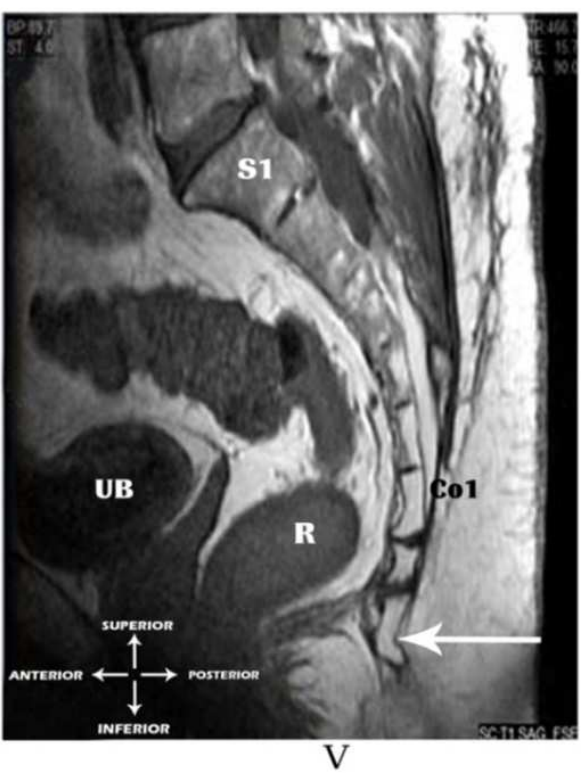

Fig. (6). A photograph of MRI (lateral view) of a female 33 year old showing Type V coccyx (Coccygeal retroversion with bony spicule).

\section{References}

[1] Woon JT, Stringer MD(2012). Clinical anatomy of the coccyx: A systematic review.Spine (Phila Pa 976) 2013;38(23):E14371445.

[2] Maigne JY, Doursounian L, Chatellier G.,(2000). Causes and mechanisms of common coccydynia: role of body mass index and coccygeal trauma. Spine ;25:3072-9.

[3] Karadimas EJ, Trypsiannis G, Giannoudis PV., (2010). Surgical treatment of coccygodynia: An analytic review of the literature. Eur Spine J 20:698-705.

[4] Postacchini F, Massobrio M. Idiopathic coccygodynia(1983): Analysis of fifty-one operative cases and a radiographic study 
of the normal coccyx. J Bone Joint Surg Am;65:1116-1124.

[5] Grassi R, Lombardi G, Reginelli A, Capasso F, Romano F, Floriani I, Colacurci N: Coccygeal movement: Assessment with dynamic MRI. (2007) European Journal of Radiology 61(3):473-479.

[6] Fogel GR, Cunningham PY 3rd, Esses SI.(2004). Coccygodynia: evaluation and management. J Am Acad Orthop Surg;12:49-54.

[7] Karadimas EJ, Trypsiannis G, Giannoudis PV., (2010). Surgical treatment of coccygodynia: An analytic review of the literature. Eur Spine J 20:698-705.

[8] Kerimoglu U, Dagoglu MG, Ergen FB., (2007). Intercoccygeal angle and type of coccyx in asymptomatic patients. Surg Radiol Anat 29:683-687.

[9] Kim NH., and Suk KS(1999): Clinical and radiological differences between traumatic and idiopathic coccygodynia. Yonsei Med J 40:215-220.

[10] O'Rahilly R, Muller F, Meyer DB. 1990. The human vertebral column at the end of the embryonic period proper. 4 . The sacrococcygeal region. J Anat 168:95-111.

[11] Tague RG (2011) Fusion of coccyx to sacrum in humans: prevalence,correlates, and effect on pelvic size, with obstetrical and evolutionary implications. Am J Phys Anthropol 145:426-437.

[12] Wray C, Easom S, Hoskinson J.(1999) Coccydynia: aetiology and treatment. J Bone Joint Surg Br ; 73:335-338.
[13] Pelin C, Duyar I, Kayahan EM, Conti A, Maestroni GJ, Cosentino M (2005). Body height estimation based on dimensions of sacral and coccygeal vertebrae. J Forensic Sci 50:294-297.

[14] Guvencer M, Dalbayrak S, Tayefi H, Gatalica Z, Wang L, Lucio ET, Miettinen M. (2009). Surgical anatomy of the presacral area. Surg Radiol Anat 31:251-257.

[15] Doursounian L, Maigne JY, Faure F, Chatellier G(2004). Coccygectomy for instability of the coccyx. Int Orthop 28:176-179.

[16] Balain B, Eisenstein SM, Alo GO, Ga'spa'r L, Jo'na's Z, Kiss (2006) Coccygectomy for coccydynia: case series and review of literature. Spine ;31:E414-20.

[17] Maigne JY, Tamalet B., (1996). Standardized radiologic protocol for the study of common coccygodynia and characteristics of the lesions observed in the sitting position. Clinical elements differentiating luxation, hypermobility, and normal mobility. Spine 21:2588-2593.

[18] Nathan ST, Fisher BE, Roberts CS., (2010). Coccydynia: A review of pathoanatomy, aetiology, treatment and outcome. J Bone Joint Surg Br 92:1622-1627.

[19] Patijn J, Janssen M, Hayek S, Nathan ST, Fisher BE, Roberts CS., (2010).. Coccygodynia. Pain Pract 10:554-559.

[20] Pennekamp PH, Kraft CN, Stutz A, Hammer N, Steinke H, Slowik V (2005). Coccygectomy for coccygodynia: J Trauma;59:1414-19. 